\title{
Effects of Drought Stress on Photosynthetic and Physiological Parameters of Tomato
}

\author{
Guoting Liang, Junhui Liu, and Jingmin Zhang \\ Facility Horticulture Laboratory of Universities in Shandong, Weifang University of Science and \\ Technology, Weifang, Shandong, China \\ Jing Guo \\ Mountain Tai Forest Ecosystem Research Station of State Forestry and Grassland Administration, \\ Forestry College of Shandong Agricultural University, Taian, Shandong, China
}

\begin{abstract}
AdDitional INDEX words. antioxidant enzymes, chlorophyll fluorescence, gas exchange, Solanum lycopersicum
Abstract. Drought has become an important factor limiting crop yields in China. As an important greenhouse horticultural crop in China, the research of tomato (Solanum lycopersicum L. cv. Jinpeng No.10) is of great theoretical and practical significance. In the study, four different relative soil moisture contents $(74 \%$ to $80 \%, 55 \%$ to $61 \%, 47 \%$ to $52 \%$, and $25 \%$ to $30 \%$ ) were used to induce drought stress. We investigated changes in photosynthetic gas exchange, chlorophyll fluorescence, and other related physiological parameters in response to different relative soil moisture contents. Drought inhibited the photosynthesis of tomato significantly, as shown by a clear decline in the net photosynthetic rate. Our results indicated stomatal limitation and nonstomatal limitation were responsible for the photosynthesis reduction.
\end{abstract}

Recently, under the influence of global climate change, drought has occurred more frequently and seriously, with most countries and regions being threatened by drought to varying degrees (Fullana-Pericàs et al., 2018; Lehner et al., 2006; Lesk et al., 2016). The rational use of water resources has become a worldwide problem (Cominelli et al., 2009; Yan and Wang, 2013). China is one of the countries suffering the shortage of water resources (Feng and Liu, 2006; Jiang, 2009). Due to the shortage and uneven distribution of water resources, water has become an important factor limiting crop yields in China (Miao et al., 2017).

Crop losses caused by drought are the highest among losses caused by all abiotic stresses (Placide et al., 2014). Drought can influence water metabolism in plants and cause significant changes in plant morphology, physiology, and biochemistry (Torres-Ruiz et al., 2015). Therefore, more research into the responses and adaptation mechanisms of crops to drought stress is needed to develop tolerant and high water-use-efficiency crop systems in agriculture.

Drought stress restricts plant growth by decreasing photosynthetic rate (Kebbas et al., 2015; Zhang et al., 2018). The main factors responsible for decreased photosynthesis could be stomatal (stomatal closure due to decreased $\mathrm{CO}_{2}$ ), nonstomatal (decreased photosynthetic activity in mesophyll tissue), or both (Ghotbi-Ravandi et al., 2014; Varone et al., 2012). These factors (stomatal, nonstomatal, or both) depend on experimental treatment as well as species, cultivar, age, and development

Received for publication 23 Apr. 2019. Accepted for publication 7 Sept. 2019 Published online 27 November 2019.

This work was supported by Science Research Projects of Facility Horticulture Laboratory of Universities in Shandong (2018YY031), National Natural Science Foundation of China (31770706), National Natural Science Foundation of China (31870379), and Key Research and Development (Commonweal) Project of Shandong Province (2019GSF109113).

G.L. and J.G. are corresponding authors. E-mail: lgt1984@wfust.edu.cn or jingguo@sdau.edu.cn.

This is an open access article distributed under the CC BY-NC-ND license (https://creativecommons.org/licenses/by-nc-nd/4.0/). status of the plants being studied (Liang et al., 2018; Liu et al., 2017).

Under stress, plants can reduce the production of excess electrons through energy dissipation mechanisms during photosynthetic electron transfer. Under drought stress, energy dissipation mechanisms, such as heat dissipation or photorespiration, play roles in the drought tolerance of plants (Flexas and Medrano, 2002). Regarding photosynthesis in leaves, gas exchange index reflects its "apparent" characteristics, while chlorophyll fluorescence reflects its "intrinsic" characteristics (Jiang et al., 2006; Long and Bernacchi, 2003). Therefore, these two parameters have been widely used in plant stress-tolerance physiology, crop breeding, and agronomy (Paleg and Aspinall, 1982).

Drought tolerance in plants is mainly manifested by effects such as the accumulation of osmotic substances, changes in membrane lipid composition, scavenging of reactive oxygen species (ROS), and regulation of protein induction and hormonal balance (Cuming et al., 2007; Martinez et al., 2004). Drought stress causes an imbalance between the production and scavenging of ROS in plants (Ajithkumar and Panneerselvam, 2014). ROS accumulation causes membrane damage and membrane lipid peroxidation (Xu et al., 2006). Several antioxidant enzymes and osmotic substances (including soluble sugars, proteins, free prolyls, and so forth) in plants constitute the antioxidant enzyme systems (Malviya, 2015; Sairam et al., 2011), which scavenge these ROS and protect macromolecules in plant cells (Ennajeh et al., 2009).

Tomato is an important greenhouse horticultural crop in China, with a wide distribution and high economic value. Moreover, tomato is a model plant of theoretical and practical significance in research (Arie et al., 2007). Although some studies have been carried out on the photosynthesis of tomato under drought stress (Brix, 2010; Jangid and Dwivedi, 2016), these studies are not systematic and comprehensive. Thus, in this study, the combination measurement of photosynthetic gas exchange, chlorophyll fluorescence, and antioxidant enzyme activities were used to identify key regulatory photosynthesis circuits under drought stress. The objective of this study was to 
provide valuable information regarding drought resistance mechanisms of plant.

\section{Materials and Methods}

Test materials and Processing. All experiments were conducted in the greenhouse of Shandong Facility Horticultural Laboratory, Weifang, Shandong Province, China. The temperature in the greenhouse was 12 to $30{ }^{\circ} \mathrm{C}$. The maximum illumination in sunny days is $518.4 \mu \mathrm{mol} \cdot \mathrm{m}^{-2} \cdot \mathrm{s}^{-1}$. Tomato seeds were planted in plug plate (Wei Nong Co., Taizhou, China). Tomato special matrix (Organic Nutrient Soil Co., Weifang, China) and vermiculite were mixed in a 3:1 ratio, the organic matter was $14 \%$ to $18 \%$, the total nitrogen was $0.4 \%$, the total phosphorus was $0.12 \%$, the available nitrogen was $0.0033 \%$, and the available phosphorus was $0.012 \%$. When plants reached the fifth true leaf stage, they were transplanted (one seedling per pot) into plastic flowerpots in early Mar. 2018. Each pot (30 cm diameter, $14 \mathrm{~cm}$ height) was spaced $1 \mathrm{~m}$ apart. Loam soil was collected from the greenhouse from areas that were planted with tomato, with $5 \mathrm{~kg}$ soil being placed in each flowerpot. Soil bulk density was $1.27 \mathrm{~g} \cdot \mathrm{cm}^{-3}$, $\mathrm{pH}$ was 6.6 to 7.2 , soil organic content was $1.23 \%$, available nitrogen was $45.12 \%$, available phosphorus was $13.18 \%$, and available potassium was $0.008 \%$. Plants were watered regularly during the drought treatment period, but no additional nutrients were applied.

The experimental treatments were applied 1 week after transplanting. Field soil capacity was $36.2 \%$. In total, 40 welldeveloped plants with similar heights and basal diameters were selected as test plants and divided into four groups (10 plants per group). Soil water content (SWC) was determined using a soil moisture tester (TDR FS6440; Spectrum Technologies, Aurora, IL) with a P3-type soil moisture probe. According to the equation, SWC was calculated as the product of field capacity (FC) and relative soil water content (RSMC). RSMC of the control (CK) was controlled at $74 \%$ to $80 \%$, that of treatment $1\left(\mathrm{~T}_{1}\right)$ at $55 \%$ to $61 \%$, that of treatment $2\left(\mathrm{~T}_{2}\right)$ at $47 \%$ to $52 \%$, and that of treatment $3\left(\mathrm{~T}_{3}\right)$ at $25 \%$ to $30 \%$. After $15 \mathrm{~d}$ of treatment, 9 of the 10 plants from each treatment condition were selected (the height for CK, T1, T2, and T3 was 45, 39, 36, and $30 \mathrm{~cm}$, respectively), and they were divided into three groups and each group was considered as a biological replicate. The third leaves from the stem end of the test plants were chosen to examine appropriate physiological and biochemical indices. Each group was measured once per day for $3 \mathrm{~d}$.

MEASUREMENT OF PHOTOSYNTHETIC GAS EXCHANGE PARAMETERS. A portable photosynthesis system (CIRAS-2; PPS Systems, Amesbury, MA) was used to measure the photosynthetic gas exchange parameters of the sampled leaves at 0830-1130 HR. The environment temperature was set at $27 \pm 3{ }^{\circ} \mathrm{C}$. During measurements, $\mathrm{CO}_{2}$ concentration, relative humidity, and air temperature in the leaf chamber were $365 \pm 5 \mu \mathrm{mol} \cdot \mathrm{m}^{-2}, 60 \% \pm$ $4.0 \%$, and $26 \pm 1.5^{\circ} \mathrm{C}$, respectively. A gradient of 14 photosynthetic active radiation $(P A R)$ settings $(2000,1800,1600,1400$, $1200,1000,800,600,400,200,150,100,50$, and $\left.0 \mu \mathrm{mol} \cdot \mathrm{m}^{-2} \cdot \mathrm{s}^{-1}\right)$ was supplied via a cold light-emitting diode (LED) irradiation source (CIRAS-2 LED; range 0 to $2000 \mu \mathrm{mol} \cdot \mathrm{m}^{-2} \cdot \mathrm{s}^{-1}$ ). Photosynthetic parameters were measured at each $P A R$ setting for 120 $\mathrm{s}$, repeating each measurement three times. The automatic portable photosynthesis system recorded $P A R$, transpiration rate $(E)$, net photosynthetic rate $\left(P_{\mathrm{N}}\right)$, stomatal conductance $\left(g_{\mathrm{s}}\right)$, the air $\mathrm{CO}_{2}$ concentration $\left(C_{\mathrm{a}}\right)$, and intercellular $\mathrm{CO}_{2}$ concentration
$\left(C_{\mathrm{i}}\right)$. Water-use efficiency $\left(W_{\mathrm{UE}}\right)$ was calculated as $W_{\mathrm{UE}}=P_{\mathrm{N}} / E$, and stomatal limitation $\left(L_{s}\right)$ was calculated as $L_{s}=1-C_{\mathrm{i}} / C_{\mathrm{a}}(\mathrm{Nijs}$ et al., 1997).

MeAsurement of CHLOROPHYLl FLUORESCENCE PARAMETERS. A portable pulse amplitude-modulated chlorophyll fluorometer (FMS-2; Hansatech, King's Lynn, UK) was used to measure chlorophyll fluorescence parameters, such as minimum chlorophyll fluorescence yield of the dark-adapted state $\left(F_{0}\right)$, maximal fluorescence yield of the dark-adapted state $\left(F_{\mathrm{M}}\right)$, steady-state fluorescence yield $\left(F_{\mathrm{S}}\right)$, minimum fluorescence of the light-adapted state $\left(F_{0}\right.$ '), and maximal fluorescence yield of the light-adapted state $\left(F_{\mathrm{M}}{ }^{\prime}\right)$. All measurements were taken three times. Under $800 \mu \mathrm{mol} \cdot \mathrm{m}^{-2} \cdot \mathrm{s}^{-1}$ light, the leaves of each treated plant reached steady state after photochemistry, $F_{\mathrm{S}}$ was measured; then under saturated pulsed light $\left(12,000 \mu \mathrm{mol} \cdot \mathrm{m}^{-2} \cdot \mathrm{s}^{-1}\right), F_{\mathrm{M}}$ ' was measured. Then the action light was closed and the far red light was turned on immediately; $F_{0}$ ' was measured after $2 \mathrm{~s}$. After that, dark treatment was carried out for $30 \mathrm{~min}$ with a dark adaptation clip; $F_{0}$ and $F_{\mathrm{M}}$ were measured.

Other chlorophyll fluorescence parameters were calculated according to the following equations: maximal quantum yield of photosystem II (PSII) photochemistry: $F_{\mathrm{V}} / F_{\mathrm{M}}=\left(F_{\mathrm{M}}-F_{0}\right) / F_{\mathrm{M}}$; photochemical quenching coefficient: $q_{\mathrm{P}}=\left(F_{\mathrm{M}}{ }^{\prime}-F_{\mathrm{S}}\right) /\left(F_{\mathrm{M}}{ }^{\prime}-F_{0}{ }^{\prime}\right)$; nonphotochemical quenching: $\mathrm{NPQ}=\left(F_{\mathrm{M}}-F_{\mathrm{M}}{ }^{\prime}\right) / F_{\mathrm{M}}{ }^{\prime}$; and effective quantum yield of PSII photochemistry: $\Phi_{\mathrm{PSII}}=\left(F_{\mathrm{M}}{ }^{\prime}-F_{\mathrm{S}}\right) / F_{\mathrm{M}}$ ' (Liang et al., 2017).

Measurement of antioxidant ENZYMe aCtivities AND MALONDIALDEHYDE CONCENTRATION. The antioxidant enzyme activities [(superoxide dismutase (SOD), peroxidase (POD), and catalase (CAT)], and malondialdehyde (MDA) concentration were measured with the corresponding reagent kits for plant tissue (Jiancheng, Nanjing, China), following the manufacturer's protocols. SOD activity was determined by xanthine oxidase method (Xu et al., 2011), POD activity was measured by guaiacol method (Cazenave et al., 2006), CAT activity was determined by potassium permanganate titration (Jiang et al., 2009), MDA content was measured by thiobarbituric acid (TBA) method (Schmedes and Hølmer, 1989). An ultraviolet-visible spectrophotometer (ultraviolet-265; Shimadzu, Kyoto, Japan) was used to measure the light absorption value.

Photosynthesis-light Response Curves. Ye and Yu (2007) demonstrated that response curves of $P_{\mathrm{N}}$ to light intensity could be accurately fitted by the rectangular hyperbolic correction model. The light response parameters were analyzed using SPSS (version 17.0; IBM Corp., Armonk, NY) software. Equations for the rectangular hyperbolic correction model were as follows:

$$
\begin{aligned}
P_{\mathrm{N}} & =\Phi \frac{1-\beta P_{\mathrm{AR}}}{1+\gamma P_{\mathrm{AR}}} P_{\mathrm{AR}}-R_{\mathrm{D}} \\
L_{\mathrm{SP}} & =\frac{\sqrt{(\beta+\gamma) / \beta-1}}{\gamma} \\
P_{\mathrm{N} \max } & =\Phi\left(\frac{\sqrt{\beta+\gamma}-\sqrt{\beta}}{\gamma}\right)^{2}-R_{\mathrm{D}}
\end{aligned}
$$

Equations for quantum yield at the light compensation point $\left(\Phi_{\mathrm{C}}\right)$, intrinsic quantum yield $\left(\Phi_{0}\right)$, and the absolute value of the 
Table 1. Responses of apparent quantum yield (AQY), light saturation point (LSP), light-saturated net photosynthetic rate $\left(P_{\text {Nmax }}\right)$, light compensation point $(\mathrm{LCP})$, and respiration rate $\left(R_{\mathrm{D}}\right)$ of tomato under different soil drought stress.

\begin{tabular}{|c|c|c|c|c|c|c|c|c|c|}
\hline Light response model & Treatment $^{\mathrm{z}}$ & $\Phi_{0}^{\mathrm{y}}$ & $\Phi_{\mathrm{C}}{ }^{\mathrm{x}}$ & $\Phi_{\mathrm{C} 0}{ }^{\mathrm{w}}$ & LSP & $P_{\mathrm{Nmax}}$ & LCP & $R_{\mathrm{D}}$ & $R^{2 \mathrm{v}}$ \\
\hline \multirow[t]{3}{*}{ Rectangular hyperbolic modified model } & $74 \%$ to $80 \%$ & 0.052095 & 0.046162 & 0.046160 & 1229 & 7.55 & 29.61 & 1.367 & 0.9991 \\
\hline & $55 \%$ to $61 \%$ & 0.048619 & 0.040738 & 0.040738 & 1157 & 7.09 & 51.97 & 2.117 & 0.9991 \\
\hline & $47 \%$ to $52 \%$ & 0.047904 & 0.038821 & 0.038822 & 1153 & 6.64 & 62.94 & 2.444 & 0.9992 \\
\hline
\end{tabular}

${ }^{\bar{z}}$ Control relative soil water content $(\mathrm{RSMC})=74 \%$ to $80 \%$, Treatment $1\left(\mathrm{~T}_{1}\right) \mathrm{RSMC}=55 \%$ to $61 \%$, Treatment $2\left(\mathrm{~T}_{2}\right) \mathrm{RSMC}=47 \%$ to $52 \%$, Treatment $3\left(\mathrm{~T}_{3}\right) \mathrm{RSMC}=25 \%$ to $30 \%$.

${ }^{\mathrm{y}}$ Intrinsic quantum yield $\left(\Phi_{0}\right)$.

${ }^{\mathrm{x}}$ Quantum yield at the light compensation point $\left(\Phi_{\mathrm{C}}\right)$.

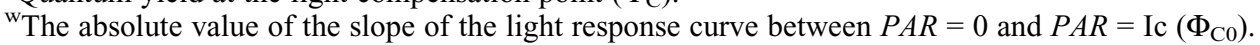

${ }^{\mathrm{v}}$ Coefficient of determination $\left(R^{2}\right)$.

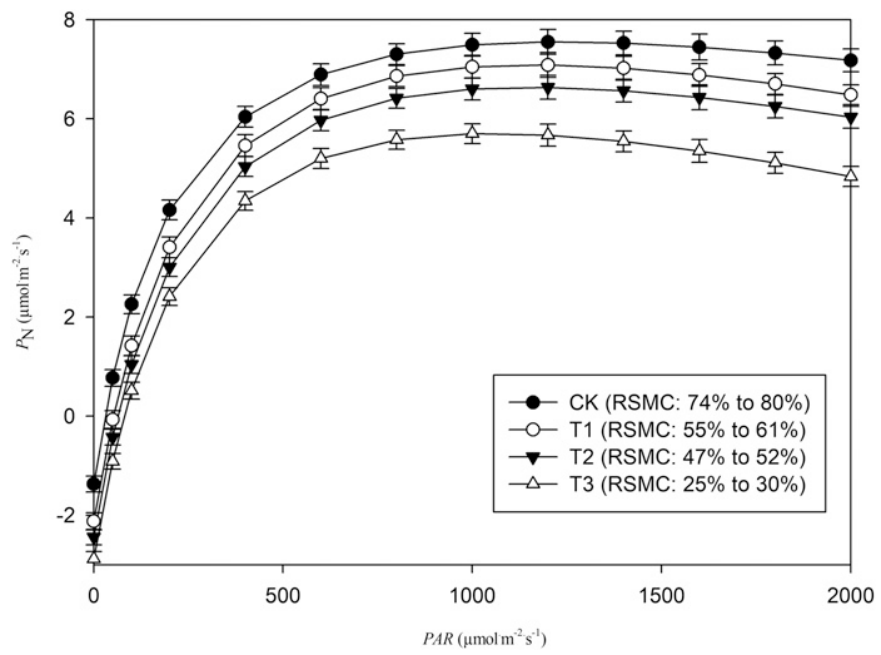

Fig. 1. Photosynthetic rate-light response curves [photosynthetically active radiation $(P A R)$, net photosynthetic rate $\left(P_{\mathrm{N}}\right)$ ] of tomato under different soil drought stress. Values are the means of three replicates \pm SD. Control $(\mathrm{CK})$ relative soil water content $(\mathrm{RSMC})=74 \%$ to $80 \%$, Treatment $1\left(\mathrm{~T}_{1}\right) \mathrm{RSMC}=$ $55 \%$ to $61 \%$, Treatment $2\left(\mathrm{~T}_{2}\right)$ RSMC $=47 \%$ to $52 \%$, Treatment $3\left(\mathrm{~T}_{3}\right)$ $\mathrm{RSMC}=25 \%$ to $30 \%$.

slope of the light response curve between $P_{\mathrm{AR}}=0$ and $P_{\mathrm{AR}}=I_{\mathrm{c}}$ $\left(\Phi_{\mathrm{C} 0}\right)$ were as follows:

$$
\begin{aligned}
& \Phi \mathrm{c}=P_{\mathrm{N}}^{\prime}\left(P_{\mathrm{AR}}=I \mathrm{c}\right)=\alpha \frac{1+(\gamma-\beta) I \mathrm{c}-\beta \gamma I \mathrm{c}^{2}}{(1+\gamma I \mathrm{c})^{2}} \\
& \Phi_{0}=P_{\mathrm{N}}^{\prime}\left(P_{\mathrm{AR}}=0\right)=\Phi \\
& \Phi_{\mathrm{c} 0}=\left|R_{\mathrm{D} / I_{\mathrm{c}}}\right|
\end{aligned}
$$

where, $P_{\mathrm{N}}{ }^{\prime}$ is one-step derivatives of $P_{\mathrm{N}} ; \Phi$ is apparent quantum yield (AQY) $\left(\mathrm{mol} \cdot \mathrm{mol}^{-1}\right) ; P_{\mathrm{AR}}$ is the photosynthetic active radiation intensity $\left(\mu \mathrm{mol} \cdot \mathrm{m}^{-2} \cdot \mathrm{s}^{-1}\right) ; L_{\mathrm{SP}}$ is the light saturation point $\left(\mu \mathrm{mol} \cdot \mathrm{m}^{-2} \cdot \mathrm{s}^{-1}\right) ; R_{\mathrm{D}}$ is respiration rate $\left(\mu \mathrm{mol} \cdot \mathrm{m}^{-2} \cdot \mathrm{s}^{-1}\right) ; \beta$ and $\gamma$ are model coefficients; $P_{\mathrm{N}}$ is net photosynthetic rate $\left(\mu \mathrm{mol} \cdot \mathrm{m}^{-2} \cdot \mathrm{s}^{-1}\right) ; P_{\mathrm{Nmax}}$ is maximum net photosynthetic rate $\left(\mu \mathrm{mol} \cdot \mathrm{m}^{-2} \cdot \mathrm{s}^{-1}\right)$; and $I_{\mathrm{c}}$ is the light compensation point $(\mathrm{LCP})\left(\mu \mathrm{mol} \cdot \mathrm{m}^{-2} \cdot \mathrm{s}^{-1}\right)$.

DAta Processing. SPSS 17.0 software and Excel (2016 for Windows; Microsoft, Redmond, WA) were employed for oneway analysis of variance and Fisher's protected least significant difference method for multiple pairwise comparisons. $P<0.05$ was considered significant. The photosynthetic light response parameters of tomato to different degrees of drought stress were based on gas exchange data, which were obtained under different light intensity and RSMC treatments ( $\mathrm{Ye}$ and $\mathrm{Yu}$, 2007).

\section{Results}

Light RESPONSE PARAMETERS. Light response parameters of tomato are listed in Table 1 . For the rectangular hyperbolic correction model between photosynthetic rate and $P A R, R^{2}$ was $>0.999$, which showed that the model closely simulated the response of the photosynthetic rate to light intensity (Liang et al., 2017).

Table 1 and Fig. 1 describe changes in light response parameters of tomato under different soil drought stress treatments. With the increase in drought stress severity, $P_{\text {Nmax }}$, $\mathrm{L}_{S P}$, and AQY all decreased, while $R_{\mathrm{D}}$ and LCP increased.

Under a stable PAR (1200 $\left.\mu \mathrm{mol} \cdot \mathrm{m}^{-2} \cdot \mathrm{s}^{-1}\right), P_{\mathrm{N}}, E, g_{\mathrm{s}}, C_{\mathrm{i}}$, $W_{\mathrm{UE}}$, and $L_{\mathrm{s}}$ all significantly changed with increasing drought stress. $P_{\mathrm{N}}, E$, and $g_{\mathrm{s}}$ all declined, with significant differences being detected among different drought treatments. $W_{\mathrm{UE}}$ decreased with increasing drought stress, suggesting that drought stress directly affected the $W_{\mathrm{UE}}$ of tomato. $L_{\mathrm{s}}$ gradually increased, showing the opposite response of decreasing $C_{\mathrm{i}}$, while $P_{\mathrm{N}}$ declined under increasing drought stress severity (Table 2).

ChLOROPHYLl FLUORESCENCE PARAMETERS. $F_{\mathrm{V}} / F_{\mathrm{M}}$ and $\Phi_{\mathrm{PSII}}$ decreased while $1-q_{\mathrm{P}}$ significantly increased with increasing severity of drought stress (Table 3). However, NPQ increased initially - then decreased as drought stress increased (Table 3).

Antioxidant enzyme activities (SOD, POD, And CAT) AND MDA CONCENTRATION. With increased severity of drought stress, the activities of the key antioxidant enzyme, namely SOD, POD, and CAT, increased initially and then decreased at low drought stress (Table 4), while MDA increased gradually but steadily as RSMC decreased and drought stress increased (Table 4).

\section{Discussion}

With the increase of the world population, the need for more crops is also increasing. However, drought stress was one of the main reasons causing the crop losses all over the world, which has aroused the attention of the scholars worldwide (Li et al., 2017). As one of the main basics for plant growth, photosynthesis is a hot topic in the study of plant responses under abiotic stress (Gururani et al., 2015; Liu et al., 2017). 
Table 2. Response of photosynthetic parameters of tomato to different soil drought stress severities under the same photosynthetically active radiation value $\left(1200 \mu \mathrm{mol} \cdot \mathrm{m}^{-2} \cdot \mathrm{s}^{-1}\right)$. Values are means of three replications.

\begin{tabular}{|c|c|c|c|c|c|c|}
\hline & $P_{\mathrm{N}}^{\mathrm{y}}\left(\mu \mathrm{mol} \cdot \mathrm{m}^{-2} \cdot \mathrm{s}^{-1}\right)$ & $E^{\mathrm{x}}\left(\mathrm{mmol} \cdot \mathrm{m}^{-2} \cdot \mathrm{s}^{-1}\right)$ & $g_{\mathrm{s}}{ }^{\mathrm{w}}\left(\mathrm{mmol} \cdot \mathrm{m}^{-2} \cdot \mathrm{s}^{-1}\right)$ & $C_{\mathrm{i}}^{\mathrm{v}}\left(\mu \mathrm{mol} \cdot \mathrm{mol}^{-1}\right)$ & $L_{\mathrm{s}}^{\mathrm{u}}$ & $\mathrm{WUE}^{\mathrm{t}}\left(\mu \mathrm{mol} \cdot \mathrm{mmol}^{-1}\right)$ \\
\hline Treatment $^{\mathrm{z}}$ & \multicolumn{6}{|c|}{$($ mean $\pm \mathrm{SD})$} \\
\hline $74 \%$ to $80 \%$ & $7.59 \pm 0.25 \mathrm{a}^{\mathrm{s}}$ & $2.05 \pm 0.05 \mathrm{a}$ & $53.42 \pm 3.09 \mathrm{a}$ & $275.72 \pm 2.33 \mathrm{a}$ & $0.24 \pm 0.06 \mathrm{c}$ & $3.70 \pm 0.04 \mathrm{a}$ \\
\hline $55 \%$ to $61 \%$ & $7.07 \pm 0.26 \mathrm{~b}$ & $1.96 \pm 0.06 \mathrm{ab}$ & $49.57 \pm 0.45 b$ & $271.00 \pm 1.23 \mathrm{ab}$ & $0.25 \pm 0.03 \mathrm{bc}$ & $3.61 \pm 0.03 \mathrm{~b}$ \\
\hline $47 \%$ to $52 \%$ & $6.62 \pm 0.24 b$ & $1.87 \pm 0.06 \mathrm{~b}$ & $47.18 \pm 2.32 b$ & $260.89 \pm 5.39 \mathrm{c}$ & $0.29 \pm 0.14 \mathrm{a}$ & $3.55 \pm 0.02 \mathrm{c}$ \\
\hline $25 \%$ to $30 \%$ & $5.60 \pm 0.22 \mathrm{c}$ & $1.61 \pm 0.06 \mathrm{c}$ & $38.28 \pm 1.20 \mathrm{c}$ & $269.82 \pm 1.24 \mathrm{~b}$ & $0.26 \pm 0.03 \mathrm{~b}$ & $3.49 \pm 0.01 \mathrm{~d}$ \\
\hline
\end{tabular}

${ }^{\mathrm{z}}$ Control relative soil water content $(\mathrm{RSMC})=74 \%$ to $80 \%$, Treatment $1\left(\mathrm{~T}_{1}\right) \mathrm{RSMC}=55 \%$ to $61 \%$, Treatment $2\left(\mathrm{~T}_{2}\right) \mathrm{RSMC}=47 \%$ to $52 \%$, Treatment $3\left(\mathrm{~T}_{3}\right) \mathrm{RSMC}=25 \%$ to $30 \%$.

${ }^{\mathrm{y}}$ Net photosynthetic rate $\left(P_{\mathrm{N}}\right)$.

${ }^{\mathrm{x}}$ Transpiration rate $(E)$.

${ }^{\mathrm{w}}$ Stomatal conductance $\left(g_{\mathrm{s}}\right)$.

${ }^{v}$ Intercellular $\mathrm{CO}_{2}$ concentration $\left(C_{\mathrm{i}}\right)$.

${ }^{\mathrm{u}}$ Stomatal limitation $\left(L_{\mathrm{s}}\right)$

${ }^{\mathrm{t}}$ Water-use efficiency (WUE).

${ }^{\mathrm{s}}$ Means in columns under different soil drought stress followed by different letters are significantly different (LSD test, $P<0.05$ ).

Table 3. Effects of soil drought stress on chlorophyll fluorescence parameters of tomato. Values are means of three replications.

\begin{tabular}{lllll}
\hline & \multicolumn{1}{c}{$F_{\mathrm{v}} / F_{\mathrm{m}}{ }^{\mathrm{y}}$} & \multicolumn{1}{c}{$1-\mathrm{q}_{\mathrm{P}}^{\mathrm{x}}$} & NPQ $^{\mathrm{w}}$ & ФPSII $^{\mathrm{v}}$ \\
\cline { 2 - 5 } Treatment $^{\mathrm{z}}$ & \multicolumn{4}{c}{$($ mean $\pm \mathrm{SD})$} \\
\hline $74 \%$ to $80 \%$ & $0.843 \pm 0.009 \mathrm{ab}^{\mathrm{u}}$ & $0.239 \pm 0.013 \mathrm{~b}$ & $0.701 \pm 0.009 \mathrm{~d}$ & $0.752 \pm 0.008 \mathrm{a}$ \\
$55 \%$ to $61 \%$ & $0.839 \pm 0.04 \mathrm{abc}$ & $0.281 \pm 0.059 \mathrm{ab}$ & $0.787 \pm 0.007 \mathrm{c}$ & $0.623 \pm 0.006 \mathrm{~b}$ \\
$47 \%$ to $52 \%$ & $0.821 \pm 0.005 \mathrm{bc}$ & $0.333 \pm 0.011 \mathrm{a}$ & $0.893 \pm 0.004 \mathrm{a}$ & $0.515 \pm 0.003 \mathrm{c}$ \\
$25 \%$ to $30 \%$ & $0.780 \pm 0.003 \mathrm{~d}$ & $0.364 \pm 0.070 \mathrm{a}$ & $0.824 \pm 0.003 \mathrm{~b}$ & $0.428 \pm 0.005 \mathrm{~d}$
\end{tabular}

${ }^{\mathrm{z}}$ Control relative soil water content $(\mathrm{RSMC})=74 \%$ to $80 \%$, Treatment $1\left(\mathrm{~T}_{1}\right) \mathrm{RSMC}=55 \%$ to $61 \%$,

Treatment $2\left(\mathrm{~T}_{2}\right) \mathrm{RSMC}=47 \%$ to $52 \%$, Treatment $3\left(\mathrm{~T}_{3}\right) \mathrm{RSMC}=25 \%$ to $30 \%$.

${ }^{\mathrm{y}}$ Maximal quantum yield of PSII $\left(F_{\mathrm{v}} / F_{\mathrm{m}}\right)$.

${ }^{\mathrm{x}}$ Photochemical quenching coefficient $\left(\mathrm{q}_{\mathrm{P}}\right)$.

${ }^{\mathrm{w}}$ Nonphotochemical quenching (NPQ).

${ }^{\vee}$ Effective quantum yield of PSII photochemistry (ФPSII).

${ }^{\mathrm{u}}$ Means in columns within different soil water contents followed by different letters are significantly different (LSD test, $P<0.05$ ).

Table 4. Changes in superoxide dismutase (SOD), peroxidase (POD), and catalase (CAT) activities, as well as malondialdehyde (MDA) content in tomato under soil drought stress. Values are means of three replications.

\begin{tabular}{lcccr}
\hline & SOD $\left(\mathrm{U} \cdot \mathrm{g} \cdot \mathrm{min}^{-1}\right)$ & POD $\left(\mathrm{U} \cdot \mathrm{g} \cdot \mathrm{min}^{-1}\right)$ & $\mathrm{CAT}\left(\mathrm{U} \cdot \mathrm{g} \cdot \mathrm{min}^{-1}\right)$ & MDA $\left(\mu \mathrm{mol}^{-} \cdot \mathrm{kg}^{-1}\right)$ \\
\cline { 2 - 5 } Treatment & \multicolumn{4}{c}{$(\mathrm{mean} \pm \mathrm{SD})$} \\
\hline $74 \%$ to $80 \%$ & $97.505 \pm 0.257 \mathrm{~d}^{\mathrm{y}}$ & $90.037 \pm 0.037 \mathrm{~d}$ & $75.760 \pm 0.845 \mathrm{~cd}$ & $4.526 \pm 0.019 \mathrm{~d}$ \\
$55 \%$ to $61 \%$ & $139.127 \pm 1.160 \mathrm{c}$ & $240.032 \pm 5.808 \mathrm{c}$ & $82.245 \pm 2.880 \mathrm{bc}$ & $7.962 \pm 0.064 \mathrm{c}$ \\
$47 \%$ to $52 \%$ & $286.385 \pm 0.795 \mathrm{a}$ & $330.071 \pm 6.317 \mathrm{a}$ & $101.570 \pm 1.154 \mathrm{a}$ & $10.641 \pm 0.173 \mathrm{~b}$ \\
$25 \%$ to $30 \%$ & $191.911 \pm 0.104 \mathrm{~b}$ & $270.816 \pm 3.148 \mathrm{~b}$ & $78.453 \pm 0.520 \mathrm{bcd}$ & $14.593 \pm 0.039 \mathrm{a}$
\end{tabular}

${ }^{\bar{z}}$ Control relative soil water content $(\mathrm{RSMC})=74 \%$ to $80 \%$, Treatment $1\left(\mathrm{~T}_{1}\right)$ RSMC $=55 \%$ to $61 \%$, Treatment $2\left(\mathrm{~T}_{2}\right) \mathrm{RSMC}=47 \%$ to $52 \%$, Treatment $3\left(\mathrm{~T}_{3}\right) \mathrm{RSMC}=25 \%$ to $30 \%$.

${ }^{\mathrm{y}}$ Different letters indicate significant differences (LSD test, $P<0.05$ ).

In this study, with the increase of drought stress, a decrease in $P_{\text {Nmax }}$ and a simultaneous increase in $R_{\mathrm{D}}$ imply lower photosynthetic rates and higher respiration rates. Increases in LCP and decreases in $\mathrm{L}_{S P}$ indicate that light-use efficiency (under both weak and strong light) declined as RSMC decreased. Decreasing $\Phi(\mathrm{AQY})$ suggested a decline in the use and transformation efficiency of low-light energy (Farquhar and Sharkey, 1982). It was apparent that photosynthetic rate and light-use efficiency were both inhibited by drought stress.

Changes in photosynthetic parameters under different levels of drought stress are mainly caused by stomatal or nonstomatal factors, which are reflected in changes in $C_{\mathrm{i}}$ and/or $L_{\mathrm{s}}$, as $C_{\mathrm{a}}$ is relatively stable. When decreased $P_{\mathrm{N}}$ as a result of drought stress is accompanied by increased (or unchanged) $C_{\mathrm{i}}$ and decreased $L_{\mathrm{s}}$, nonstomatal factors are the main cause of reduced photosynthetic rate. In contrast, when decreased $P_{\mathrm{N}}$ is accompanied by unchanged or increased $L_{\mathrm{s}}$, while $C_{\mathrm{i}}$ is unchanged or decreased, stomatal factors are the main cause (Farquhar and Sharkey, 1982). In this study, when the RSMC was $<47 \%$ to $52 \%$, any increase in drought stress and corresponding decrease in $P_{\mathrm{N}}$ were associated with decreased $C_{\mathrm{i}}$ and increased $L_{\mathrm{s}}$, suggesting that stomatal limitation was responsible for reduced $P_{\mathrm{N}}$ in tomato leaves. However, when RSMC was $>52 \%$, any increase in drought stress and corresponding decrease in $P_{\mathrm{N}}$ were accompanied by increased $C_{\mathrm{i}}$ and decreased $L_{\mathrm{s}}$, indicating that nonstomatal limitation was responsible for reduced $P_{\mathrm{N}}$. Under these conditions, the photosynthetic apparatus was damaged.

Changes in $W_{\mathrm{UE}}$ by plants are regulated by coordinating the association between carbon assimilation and water consumption, which is an important strategy used by plants to withstand drought. In this study, $P_{\mathrm{N}}, E$, and $W_{\mathrm{UE}}$ of tomato leaves all showed similar responses to soil moisture deficits, each parameter decreasing as RSMC decreased (Table 2).

During plant photosynthesis, light energy absorbed by chloroplasts is dissipated through three reciprocally related pathways: photosynthetic electron transport, chlorophyll fluorescence, and heat dissipation (Hendrickson et al., 2004). $F_{\mathrm{V}} / F_{\mathrm{M}}$ reflects the ability of antenna pigments to absorb and convert light energy to PSII (Mckew et al., 2013). Representing the proportion of light energy is $\Phi_{\mathrm{PSII}}$, which is used for the 
photochemical reaction (Ma and Guo, 2014); and NPQ represents the heat dissipation in PSII and reflects the amount of heat dissipated from light energy absorbed by the PSII antenna pigments (Stefanov and Terashima, 2008). The excitation energy used in the PSII reaction center, $q_{\mathrm{P}}$, reflects the electron transfer activity of the PSII center (Yokono et al., 2015).

In the current study, with an increase in the degree of drought stress, $F_{\mathrm{V}} / F_{\mathrm{M}}, \Phi_{\mathrm{PSII}}$, and $q_{\mathrm{P}}$ gradually decreased, suggesting that drought initiated the closure of the PSII reaction center, limiting electron transfer and reducing the light energy available for actual photochemical reactions in the PSII reaction center (Stefanov and Terashima, 2008). Maximum $F_{\mathrm{V}} / F_{\mathrm{M}}$ is reflective of potential maximum photosynthetic capacity of plant leaves under nonstressful conditions after a sufficient dark adaptation. $F_{\mathrm{V}} / F_{\mathrm{M}}$ reflects the potential maximum photosynthetic capacity of plant leaves after a sufficiently dark adaptation (Sharma et al., 2015). $F_{\mathrm{V}} / F_{\mathrm{M}}$ is relatively constant, generally between 0.8 and 0.85 ; but it also varies with plant cultivars $(\mathrm{Xu}, 2002)$. When plants are stressed, $F_{\mathrm{V}} / F_{\mathrm{M}}$ decreases, depending on the plant cultivar and growth status $(\mathrm{Xu}, 2002)$. In this experiment, with the increase of drought stress, $F_{\mathrm{V}} / F_{\mathrm{M}}$ decreased. In the range of RSMC $47 \%$ to $80 \%$, the differences between the values of $F_{\mathrm{V}} / F_{\mathrm{M}}$ is not significant. However, when the RSMC was in the range of $25 \%$ to $30 \%$, $F_{\mathrm{V}} / F_{\mathrm{M}}$ was decreased significantly. NPQ initially increased as drought stress increased and then decreased; this finding suggests that tomato leaves dissipated excess excitation energy by heat dissipation under mild drought stress, which effectively released photoinhibition and photooxidation triggered by excessive energy absorbed by the PSII reaction center. As drought stress increased, the heat dissipation capacity reduced, and PSII was damaged (Hendrickson et al., 2004).

As the key enzymes scavenging ROS, SOD, POD, and CAT play important roles in regulating ROS accumulation. In the current study, changes in SOD, POD, and CAT activities and associated changes in MDA concentrations in tomato leaves under drought stress were analyzed. With an increase in drought stress, MDA concentration increased; this result indicated that under drought stress, the balance of the antioxidant enzyme system in plants was disrupted, resulting in ROS accumulation and increased peroxidation of membrane lipids, eventually causing membrane damage. Above a certain level of stress, which coincided with the maximum level of tolerance to drought stress of tomato seedlings (corresponding to $\mathrm{RSMC}=$ $47 \%$ to $52 \%$ ), drought stress damaged the antioxidant enzyme system and reduced enzyme activity. These results are in consistent with the result of NPQ, which indicate that with the increase of drought stress, the PSII reaction center was damaged by ROS. Several studies have reported on the association between the activity of the antioxidant enzyme system and drought tolerance in plants but with variable and inconsistent results ( $\mathrm{Li}$ et al., 2010, 2017). This variation may be caused by the activity of the antioxidant enzyme system and antioxidant concentration, among many other factors.

In conclusion, drought stress affects photosynthetic activity by disrupting the energy balance between the capacity to absorb and use light energy during photosynthesis (Pinheiro and Chaves, 2011). In this study, the response of tomato photosynthesis to drought stress transitioned from stomatal limitation to nonstomatal limitation as the stress severity increased. Due to stomatal closure, photosynthesis is decreased and the demand for NADPH in Calvin cycle reduces, which leads to the excessive reduction of photosynthetic electron transport chains and the blockage of photosynthetic electron transport. In this way, the photosynthetic electron transport branch reaction (with molecular oxygen as the acceptor) is enhanced, resulting in the formation of destructive singlet oxygen $\left({ }^{1} \mathrm{O}_{2}\right)$. Superoxide anion free radicals $\left(\mathrm{O}_{2} \cdot\right)$ and hydrogen peroxide $\left(\mathrm{H}_{2} \mathrm{O}_{2}\right)$ are two kinds of ROS produced during the metabolism of organisms, which have strong oxidative damage to cell membrane lipids. SOD, POD, and CAT are key enzymes for scavenging ROS in cells and play an important role in scavenging ROS. Under normal environmental conditions, the metabolism of reactive oxygen species in plants is in a dynamic balance of continuous production and elimination, which does not easily lead to membrane lipid peroxidation. When drought stress is aggravated, a large amount of reactive oxygen species such as ${ }^{1} \mathrm{O}_{2}, \mathrm{O}_{2} \cdot$ and $\mathrm{H}_{2} \mathrm{O}_{2}$ accumulated. These reactive oxygen species can be converted into more active $\cdot \mathrm{OH}$ via the Haber-Weiss reaction and Fenton reaction. Thus, membrane lipid peroxidation was aggravated, and MDA content of tomato seedlings increased significantly. At the same time, the chloroplast membrane was damaged and the PSII reaction center was damaged, resulting in a significant decrease in photosynthetic rate. The nonstomatal limitation occurred. The decrease of photosynthetic rate will further aggravate the imbalance of reactive oxygen species metabolism.

\section{Literature Cited}

Ajithkumar, I.P. and R. Panneerselvam. 2014. ROS scavenging system, osmotic maintenance, pigment and growth status of Panicum sumatrense Roth. under drought stress. Cell Biochem. Biophys. 68:587-595.

Arie, T., H. Takahashi, M. Kodama, and T. Teraoka. 2007. Tomato as a model plant for plant-pathogen interactions. Plant Tissue Cult. Lett. 24:135-147.

Brix, H. 2010. The effect of water stress on the rates of photosynthesis and respiration in tomato plants and loblolly pine seedlings. Physiol. Plant. 15:10-20.

Cazenave, J., M. de los Angeles Bistoni, S.F. Pesce, and D.A. Wunderlin. 2006. Differential detoxification and antioxidant response in diverse organs of Corydoras paleatus experimentally exposed to microcystin-RR. Aquat. Toxicol. 76:1-12.

Cominelli, E., M. Galbiati, C. Tonelli, and C. Bowler. 2009. Water: The invisible problem. EMBO Rpt. 10:671-676.

Cuming, A.C., S.H. Cho, Y. Kamisugi, H. Graham, and R.S. Quatrano. 2007. Microarray analysis of transcriptional responses to abscisic acid and osmotic, salt, and drought stress in the moss, Physcomitrella patens. New Phytol. 176:275-287.

Ennajeh, M., A.M. Vadel, and H. Khemira. 2009. Osmoregulation and osmoprotection in the leaf cells of two olive cultivars subjected to severe water deficit. Acta Physiol. Plant. 31:711-721.

Farquhar, G.D. and T.D. Sharkey. 1982. Stomatal conductance and photosynthesis. Annu. Rev. Plant Physiol. 33:317-345.

Feng, Z.M. and D.W. Liu. 2006. A study on water resources carrying capacity in Jingjinji region. J. Nat. Resour. 21:689-699.

Flexas, J. and H. Medrano. 2002. Energy dissipation in C3 plants under drought. Funct. Plant Biol. 29:1209-1215.

Fullana-Pericàs, M., J. Ponce, M.A. Conesa, A. Juan, M. Ribas-Carbó, and J. Galmés. 2018. Changes in yield, growth and photosynthesis in a drought-adapted Mediterranean tomato landrace (Solanum lycopersicum 'Ramellet') when grafted onto commercial rootstocks and solanum pimpinellifolium. Scientia Hort. 233:70-77.

Ghotbi-Ravandi, A.A., M. Shahbazi, M. Shariati, and P. Mulo. 2014. Effects of mild and severe drought stress on photosynthetic efficiency in tolerant and susceptible barley (Hordeum vulgare L.) genotypes. J. Agron. Crop Sci. 200:403-415. 
Gururani, M.A., J. Venkatesh, and L.-S.P. Tran. 2015. Regulation of photosynthesis during abiotic stress-induced photoinhibition. Mol. Plant 8:1304-1320.

Hendrickson, L., R.T. Furbank, and W.S. Chow. 2004. A simple alternative approach to assessing the fate of absorbed light energy using chlorophyll fluorescence. Photosynth. Res. 82:73-81.

Jangid, K.K. and P. Dwivedi. 2016. Physiological responses of drought stress in tomato: A review. Intl. J. Agr. Environ. Biotechnol. 9:53-61.

Jiang, Q., D. Roche, T.A. Monaco, and S. Durham. 2006. Gas exchange, chlorophyll fluorescence parameters and carbon isotope discrimination of 14 barley genetic lines in response to salinity. Field Crops Res. 96:269-278.

Jiang, Y. 2009. China's water scarcity. J. Environ. Manage. 90:31853196.

Jiang, Z., B. Weng, J. Lei, Y. Wang, X. Tang, and S. Xiao. 2009. Effect of exogenous zinc addition on cell protective enzyme activities in the fruit bodies of Lentinus giganteus. Acta Microbiol. Sin. 49:11211125.

Kebbas, S., S. Lutts, and F. Aid. 2015. Effect of drought stress on the photosynthesis of Acacia tortilis subsp. raddiana at the young seedling stage. Photosynthetica 53:1-11.

Lehner, B., P. Döll, J. Alcamo, T. Henrichs, and F. Kaspar. 2006. Estimating the impact of global change on flood and drought risks in Europe: A continental, integrated analysis. Clim. Change 75:273299.

Lesk, C., P. Rowhani, and N. Ramankutty. 2016. Influence of extreme weather disasters on global crop production. Nature 529(7584):8487.

Li, D., C. Li, H. Sun, W. Wang, L. Liu, and Y. Zhang. 2010. Effects of drought on soluble protein content and protective enzyme system in cotton leaves. Front. Agr. China 4:56-62.

Li, J., Z. Cang, J. Feng, X. Bai, Z. Ding, and R. Zhai. 2017. Influence of drought stress on photosynthetic characteristics and protective enzymes of potato at seedling stage. J. Saudi Soc. Agr. Sci. 16:82-88.

Liang, G., J. Bu, S. Zhang, G. Jing, G. Zhang, and X. Liu. 2018. Effects of drought stress on the photosynthetic physiological parameters of Populus $\times$ euramericana 'Neva'. J. For. Res. 30:409-416.

Liang, G.T., S.Y. Zhang, J. Guo, R. Yang, H. Li, X.C. Fang, and G.C. Zhang. 2017. The effects of para-hydroxybenzoic acid treatment on photosynthetic parameters of Populus $\times$ euramericana 'Neva'. Photosynthetica 56:505-511.

Liu, J., R. Zhang, G. Zhang, G. Jing, and D. Zhi. 2017. Effects of soil drought on photosynthetic traits and antioxidant enzyme activities in Hippophae rhamnoides seedlings. J. For. Res. 28:255-263.

Long, S.P. and C.J. Bernacchi. 2003. Gas exchange measurements, what can they tell us about the underlying limitations to photosynthesis? Procedures and sources of error. J. Expt. Bot. 54:2393-2401.

Ma, Y.H. and S.R. Guo. 2014. 24-epibrassinolide improves cucumber photosynthesis under hypoxia by increasing $\mathrm{CO}_{2}$ assimilation and photosystem II efficiency. Photosynthetica 52:96-104.

Malviya, M.M. 2015. Effect of salt stress on growth parameter, lipid peroxidation, antioxidant enzymes and lignans of sesame. Acta Physiol. Plant. 34:2349-2358.

Martinez, J.P., S. Lutts, A.M. Bajji, and J.M. Kinet. 2004. Is osmotic adjustment required for water stress resistance in the Mediterranean shrub Atriplex halimus L? J. Plant Physiol. 161:1041-1051.

Mckew, B.A., P. Davey, S.J. Finch, J. Hopkins, S.C. Lefebvre, M.V. Metodiev, K. Oxborough, C.A. Raines, T. Lawson, and R.J. Geider. 2013. The trade-off between the light-harvesting and photoprotective functions of fucoxanthin-chlorophyll proteins dominates light acclimation in Emiliania huxleyi (clone CCMP 1516). New Phytol. 200:74-85.
Miao, Z., L. Chu, M. Xiao, and B. Cai. 2017. Advances in effect of water-saving irrigation on physiological and biochemical characteristics of tea. J. Drain. Irrig. Mach. Eng. 35:515-519.

Nijs, I., R. Ferris, H. Blum, G. Hendrey, and I. Impens. 1997. Stomatal regulation in a changing climate: A field study using free air temperature increase (FATI) and free air $\mathrm{CO}_{2}$ enrichment (FACE). Plant Cell Environ. 20:1041-1050.

Paleg, L.G. and D. Aspinall. 1982. Water stress in plants. Science 217:47-48.

Pinheiro, C. and M.M. Chaves. 2011. Photosynthesis and drought: Can we make metabolic connections from available data? J. Expt. Bot. 62:869-882.

Placide, R., G.B. Hirut, N. Stephan, and B. Fekadu. 2014. Assessment of drought stress tolerance in root and tuber crops. Afr. J. Plant Sci. 8:214-224.

Sairam, R.K., B. Vasanthan, and A. Arora. 2011. Calcium regulates Gladiolus flower senescence by influencing antioxidative enzymes activity. Acta Physiol. Plant. 33:1897-1904.

Schmedes, A. and G. Hølmer. 1989. A new thiobarbituric acid (TBA) method for determining free malondialdehyde (MDA) and hydroperoxides selectively as a measure of lipid peroxidation. J. Amer. Oil Chem. Soc. 66:813-817.

Sharma, D.K., S.B. Andersen, C.O. Ottosen, and E. Rosenqvist. 2015. Wheat cultivars selected for high $\mathrm{F}_{\mathrm{v}} / \mathrm{F}_{\mathrm{m}}$ under heat stress maintain high photosynthesis, total chlorophyll, stomatal conductance, transpiration and dry matter. Physiol. Plant. 153:284-298.

Stefanov, D. and I. Terashima. 2008. Non-photochemical loss in PSII in high- and low-light-grown leaves of Vicia faba quantified by several fluorescence parameters including $\mathrm{L}_{\mathrm{NP}}, \mathrm{F}_{0} / \mathrm{F}^{\prime}{ }_{\mathrm{m}}$, a novel parameter. Physiol. Plant. 133:327-338.

Torres-Ruiz, J.M., A. Diaz-Espejo, A. Perez-Martin, and V. HernandezSantana. 2015. Role of hydraulic and chemical signals in leaves, stems and roots in the stomatal behaviour of olive trees under water stress and recovery conditions. Tree Physiol. 35:415-424.

Varone, L., M. Ribas-Carbo, C. Cardona, A. Gallé, H. Medrano, L. Gratani, and J. Flexas. 2012. Stomatal and non-stomatal limitations to photosynthesis in seedlings and saplings of Mediterranean species pre-conditioned and aged in nurseries: Different response to water stress. Environ. Exp. Bot. 75:235-247.

Xu, D.Q. 2002. Photosynthetic efficiency. Shanghai Sci. Technol. Press, Shanghai, China.

Xu, D., J. Zhao, H.C. Hang, and J. Wen. 2011. Determination of SOD specific activity in animal and plant tissues by improved xanthine oxidase method. Food Sci. 32:237-241.

Xu, S., J. Li, X. Zhang, H. Wei, and L. Cui. 2006. Effects of heat acclimation pretreatment on changes of membrane lipid peroxidation, antioxidant metabolites, and ultrastructure of chloroplasts in two cool-season turfgrass species under heat stress. Environ. Exp. Bot. 56:274-285.

Yan, B. and G. Wang. 2013. The development situation and countermeasure of reclaimed water reuse in Zhanjiang City. Guangdong Province. Ecol. Sci. 32:668-672.

Ye, Z.P. and Q. Yu. 2007. Comparison of a new model of light response of photosynthesis with traditional models. J. Shenyang Agr. Univ. 38:771-775.

Yokono, M., R. Nagao, T. Tomo, and S. Akimoto. 2015. Regulation of excitation energy transfer in diatom PSII dimer: How does it change the destination of excitation energy? Biochimica Biophysica Acta Bioenergetics 1847:1274-1282.

Zhang, D., X. Jiao, Q. Du, X. Song, and J. Li. 2018. Reducing the excessive evaporative demand improved photosynthesis capacity at low costs of irrigation via regulating water driving force and moderating plant water stress of two tomato cultivars. Agr. Water Mgt. 199:22-33. 